\title{
Metabolic syndrome and its effect on aortic stiffness in premenopausal women
}

\author{
Simkova $\mathrm{A}^{1}$, Bulas $\mathrm{J}^{1}$, Balogova $\mathrm{S}^{1}$, Reptova $\mathrm{A}^{1}$, Kisa $\mathrm{B}^{1}$, Luha $\mathrm{J}^{2}$, Kinova $\mathrm{S}^{1}$ \\ Ist Department of Internal Medicine, Faculty of Medicine, Comenius University, Bratislava, Slovakia. \\ adriana.simkova@windowslive.com
}

\begin{abstract}
Background: Metabolic syndrome (MS) is a cluster of proatherogenic risk factors (RF) (abdominal obesity, atherogenic dyslipidemia, impaired fasting glucose or type 2 diabetes mellitus, higher blood pressure or antihypertensive therapy) that move patients into a higher risk for development of cardiovascular disease (CVD) and type 2 diabetes. The preclinical (subclinical) target organ diseases (SOD) are early signs of atherosclerosis. An increased aortic stiffness characterised by an increased pulse wave velocity in aorta (PWV Ao) is one of SOD. The aim of the present study was to assess the impact of metabolic syndrome (MS) on aortic wall stiffness and the risk profile in premenopausal women.

Methods: The aortic stiffness was measured using Arteriograph-Tensiomed, based on oscillometric measurement and analysis of the shape of brachial pulse wave, giving the PWV Ao. The results of measurements characterise a global aortic stiffness.

Results: We examined 81 premenopausal women (without history of CVD). The MS (according to the 2009 "harmonizing" definition) was present in 31 women (mean age $41.5 \mathrm{y}$ ), in the control group, there were 50 women (39 y). The most frequent components of MS were abdominal obesity (93\% vs 42\%), arterial hypertension (68 \% vs $10 \%)$ and dyslipidemia ( $29 \%$ vs $8 \%)$. The PWV Ao was significantly higher in women with MS $(9.26 \mathrm{~m} / \mathrm{s})$ compared to the control group $(7.44 \mathrm{~m} / \mathrm{s})$.

Conclusion: The aortic stiffness in women with MS compared to controls was significantly higher despite a presumed general protective hormonal effect on cardiovascular system in women with child-bearing potential (Tab. 4, Ref. 25). Full Text in PDF www.elis.sk.

Key words: metabolic syndrome, risk factors, premenopausal women, arterial stiffness.
\end{abstract}

Cardiovascular diseases (CVD) are the most common diseases of twentieth and twenty-first centuries. Among the risk factors (RF) that accelerate the progression of atherosclerotic lesions in blood vessels belong abdominal obesity (AO), dyslipidaemia (DLP), arterial hypertension $(\mathrm{AH})$ and impaired glucose metabolism. Metabolic syndrome (MS) is a cluster of selected RF. Its prevalence in the population increases continually. We can frequently find MS also in younger age groups and even in children $(1,2)$. MS thus contributes significantly to cardiovascular morbidity and mortality. According to the MS definition, three out of five criteria must be present; they are defined either by NCEP ATP III (The National Cholesterol Education Programme, Expert Adult Treatment Panel III, 2001) or IDF (International Diabetes Federation, 2005). The year 2009 brought the so called ,harmonizing definition of MS“, which reflects the agreement of several professional societies (3). $\mathrm{AO}$ as an essential component in the older IDF definition was now

\footnotetext{
${ }^{1}$ Ist Department of Internal Medicine, Faculty of Medicine, Comenius University, Bratislava, Slovakia, and ${ }^{2}$ Institute of Biology, Faculty of Medicine, Comenius University, Bratislava, Slovakia

Address for correspondence: A. Simkova, MD, Ist Department of Internal Medicine, Faculty of Medicine, Comenius University, Mickiewiczova 13, SK-813 69, Bratislava, Slovakia.
}

Acknowledgement: This work was supported by Ministry of education SR, VEGA 1/1151/11.
Tab. 1. Criteria for clinical diagnosis of the MS (2009).

Three or more of the following five risk factors:

1. Increased waist circumference in $m e n \geq 102 \mathrm{~cm}$, women $\geq 88 \mathrm{~cm}$

2. Elevated TAG $\geq 1.7 \mathrm{mmol} / 1$ (or hypolipidemic therapy)

3. Reduced HDL in man $<1.03 \mathrm{mmol} / 1$, woman $<1.3 \mathrm{mmol} / 1$ (or hypolipidemic therapy)

4. Elevated blood pressure $\geq 130 / 85 \mathrm{mmHg}$ (or antihypertensive therapy) 5. Elevated fasting plasma glucose $\geq 5.6 \mathrm{mmol} / \mathrm{l}$ ( or antidiabetic therapy)

included as a criterion equivalent to the other parameters, and a consensus in some other values was accepted. It also re-evaluated the level of fasting plasma glucose, with more strict criteria accepted according to the IDF definition of MS. Criteria for the lipid profile remained unchanged (Tab. 1).

In the context of MS, there is an alarming increase in the prevalence of obesity in populations throughout the world (4). Galajda et al in the project „, The prevalence of diabetes mellitus in Slovakia“, organized by Slovak Diabetes Society found a significantly higher prevalence of MS in women (23.9\%) compared to men $(15.9 \%)$ in the population studied (1517 respondents) using the NCEP ATP III criteria. The acceptance of strict IDF criteria increased the overall prevalence of MS in $38.1 \%$ with no statistically significant difference between genders (5). The Slovak project NEMESYS (NEw MEtabolic SYndrom in Slovakia), with 10300 participants showed that MS has a higher prevalence in 
women (52\%) compared to men (42\%) with a statistically significant difference. The prevalence of MS was increasing with age and by almost each age decade women had a higher prevalence of MS compared to men (6). The presence of MS puts people into a higher risk for development of CVD.

Obesity as an independent RF affects women's health in every stage of their life. The distribution of health hazards arising from the presence of MS significantly depends on the age though we can find different complications in postmenopausal women comparing to women in reproductive age where we assume the protective effect of their hormonal profile on the cardiovascular risk (CVR).

Because of an asymptomatic course, MS runs long-term unrecognised and untreated, the evolution of early atherosclerotic changes initiated by MS can be missed (7). Commonly available clinical and laboratory investigation methods facilitate the diagnosis of MS. Consequently, all RF discovered in an individual person should be treated simultaneously to minimize the risk and to eliminate the potential for progression of preclinical changes progressing into a clinical disease.

Manifest disease is typically preceded by slow-paced development of preclinical - subclinical changes (subclinical or target organ disease, SOD, TOD) of the cardiovascular system (CVS). Detection of subclinical disease puts patients into a higher CVR unlike the presence of RF only. It is therefore necessary to examine the patients at a higher risk and search for organ changes namely in the heart, great vessels, kidneys, brain and eye retina (8). The presence of SOD indicates the morphological changes of the CVS in the asymptomatic stage. There is an evidence that they are found more frequently in patients with MS compared to those without $\operatorname{MS}(9,10)$.

An increased vessel wall stiffness quantified by aortic pulse wave velocity (PWV Ao) is classified as a preclinical arterial disease. This independent marker of an increased CVR is associated with the structural and functional de-arrangement of the vascular wall (and consequently hemodynamics) and is used as an important parameter for total CVR estimation (11).

The aim of the present study was to assess the impact of MS on aortic wall stiffness and the risk profile in premenopausal women.

\section{Patients and methods}

The group studied consisted of women who underwent a regular preventive examination. After a prior explanation of the purpose of this study as an extended preventive examination they have signed a consent form agreeing to be taking part in this project. A prerequisite for inclusion was premenopausal age with regular menstrual cycle preserved. The group consisted of 81
Tab. 2. Comparison of PWVao and age in the groups.

\begin{tabular}{lcccc}
\hline & Age & CI & PWV Ao $(\mathrm{m} / \mathrm{s})$ & CI \\
\hline MS yes & 41.68 & $(39.28 ; 44.07)$ & 9.29 & $(8.60 ; 9.97)$ \\
MS no & 39.06 & $(37.27 ; 0.85)$ & 7.44 & $(7.05 ; 7.84)$ \\
Signif. & $\mathrm{p}=0.08$ & $\mathrm{p}<0.01$ & & \\
\hline
\end{tabular}

PWVao was significantly influenced by the presence of MS. No statistically significant difference by age category was found.

women. We have done a basic clinical examination with detailed history focused on cardiovascular RF and concomitant therapy. The standard anthropometric and blood pressure (BP) measurements were done, too.

The aortic stiffness was examined noninvasively with the Arteriograph-Tensiomed, based on oscillometric principle detecting the pulsations of brachial artery by cuff, followed by measurement and analysis of the shape of brachial pulse wave, calculating the aortic pulse wave velocity value (PWV Ao) and some other parameters of haemodynamics (BP, pulse pressure, mean arterial pressure, ejection time, return time and pressure augmentation indices). This equipment determines the global aortic stiffness and also allows the estimation of the central systolic BP of the person (12).

The MS was defined according to the criteria of the so called "harmonizing" definition. MS was present in 31 women, in the control group, there were 50 women.

Statistical analysis was performed using the SPSS software. For the comparison, nonparametric tests were used because the numerical values were not normally distributed. Numerical variables were tested by the Mann Whitney test. For the comparison of the values represented by $1=$ presence of the phenomenon and $0=$ absence, we used contingency tables and the Fisher's exact test or Chi-squared test. A confidence interval (CI) was calculated, too. The significance between the variables was considered when the $\mathrm{p}$ - values were below $0.05(\mathrm{p}<0.05)$.

\section{Results}

The mean age of women with MS was 41.7 years, the mean age in the group without MS was 39 years, no significance was found $(\mathrm{p}=0.08)$.

The mean value of PWV Ao in patients with MS was $9.26 \mathrm{~m} / \mathrm{s}$ in comparison to $7.44 \mathrm{~m} / \mathrm{s}$ in those without MS; the difference was statistically significant $(\mathrm{p}<0.01)$ (Tab. 2).

The three most frequent RF, always in higher occurrence in the group with MS, were AO (93\% vs $42 \%)$, AH (68\% vs $10 \%)$ and $\operatorname{DLP}(29 \%$ vs $8 \%$ ). The type 2 diabetes mellitus (DM2) (present in 4 patients) occurred only in the group with MS (Tab. 3). As for the treatment of hypertension, monotherapy with ACE inhibitors was dominant, beta blockers were frequently used in combina-

Tab. 3. Occurrence of risk components in the groups.

\begin{tabular}{lcccc}
\hline & Number of patients & AO & AH & DLP \\
\hline Group together & 81 & & & \\
MS yes n $(\%)$ & $31(38.28 \%)$ & $29(93 \%)$ & $21(68 \%)$ & $4(29 \%)$ \\
MS no n $(\%)$ & $50(61.72 \%)$ & $21(42 \%)$ & $5(10 \%)$ & $9(13 \%)$ \\
\hline
\end{tabular}

Women with MS had a higher percentage incidence of abdominal obesity, hypertension, dyslipidemia a 2 type diabetes mellitus. 
Tab. 4. Characteristic of group according to waist circumference, weight, BMI and blood pressure.

\begin{tabular}{|c|c|c|c|c|c|c|c|}
\hline & \multicolumn{3}{|c|}{$\mathrm{MS}+$} & \multicolumn{3}{|c|}{ MS - } & \multirow{2}{*}{ - Mann-Whitney test } \\
\hline & mean & median & $\mathrm{CI}$ & mean & median & $\mathrm{CI}$ & \\
\hline waist circumf. & 104.68 & 103.00 & $(99.44 ; 109.91)$ & 89.11 & 87.00 & $(85.33 ; 92.89)$ & $\mathrm{p}<0.01$ \\
\hline weight & 86.32 & 85.00 & $(79.18 ; 93.47)$ & 71.48 & 67.00 & $(67.17 ; 75.79)$ & $\mathrm{p}<0.01$ \\
\hline BMI & 31.86 & 31.22 & $(29.62 ; 34.09)$ & 26.46 & 24.63 & $(24.79 ; 28.13)$ & $\mathrm{p}<0.01$ \\
\hline BP syst.. & 133.45 & 131.00 & $(126.84 ; 140.07)$ & 118.56 & 116.00 & $(114.40 ; 122.72)$ & $\mathrm{p}<0.01$ \\
\hline BP diast. & 79.87 & 80.00 & $(76.18 ; 83.57)$ & 70.60 & 70.00 & $(67.83 ; 73.37)$ & $\mathrm{p}<0.01$ \\
\hline
\end{tabular}

tion. Four patients received statins, 2 patients had fibrates. In the treatment of DM2, biguanides dominated.

Abdominal obesity has been determined by a waist circumference. The average waist size $(105 \mathrm{~cm})$ for women with MS was higher compared to the control group $(89 \mathrm{~cm})$. In the current classification of obesity using BMI, women without MS were overweighed (average BMI $=26.5 \mathrm{~kg} / \mathrm{m}^{2}$ ) and women with MS belonged to class I obesity (average BMI $=32.3 \mathrm{~kg} / \mathrm{m}^{2}$ ). Significant difference was found in the average values of weight, and systolic and diastolic BP $(\mathrm{p}<0.01)$ (Tab. 4).

\section{Discussion}

The association of MS with a higher occurrence of TOD is still a current topic. A relationship of hypertension and the presence of SOD is very well known $(13,14,15)$. Studies that investigated the effect of sex on subclinical ongoing atherosclerotic process in arteries showed that women with MS have a slightly higher incidence of SOD in comparison to men $(16,17)$.

Distensibility of arterial wall is gradually decreasing with age (18), smoking (19) and the influence of other RF. Measurement of arterial pulse wave velocity in patients with MS may be helpful in identifying those at high risk for subclinical atherosclerosis (20). In women with MS, we found an increased vessel wall stiffness, the average age difference between the groups was not statistically significant, although the average age for women with MS was about 2.5 years higher. Our results showed that MS affects PWV Ao even in younger age groups; our sample consisted of relatively young women in reproductive age. These findings are consistent with the results of Ferreira et al. who found an increased artery stiffness in young women with MS (average age 23 years). Significance of MS in men was not evaluated (21). It would be interesting to do a prospective study monitoring the stiffness of the aorta in time intervals after improving risk profile and hemodynamics by pharmacological and nonpharmacological interventions.

We found a high incidence of $\mathrm{AO}$ and hypertension among patients with MS which suggested that an increased waist circumference was associated with the $\mathrm{AH}$. Abdominal obesity induced risk of developing $\mathrm{AH}$ was about $37 \%$ in women and approximately $27 \%$ in men (22). A similar relationship between RF studied was reported in the observational epidemiological study in Brazil (23).

Based on the analysis of the weight parameters (AO, weight, $\mathrm{BMI}$ ) in both groups, taking the mean age into account, we can conclude that women in reproductive age have a higher body weight than is considered to be optimal. The prevalence of $\mathrm{AH}$ and MS increases with age and hypertensive patients have a higher incidence of MS compared to the general population $(24,25)$.

\section{Conclusion}

An increased occurrence of MS in population is tightly connected with an increasing prevalence of overweight and obesity (mainly the abdominal one). Cardiometabolic RF clustered in MS have negative influence on arterial elasticity. Our group of relatively young women with MS in a fertile age had a higher PWV Ao $(9.26 \mathrm{~m} / \mathrm{s})$ in comparison to $(7.44 \mathrm{~m} / \mathrm{s})$ the control group, which gave the evidence that MS increases aortic stiffness in women in fertile age despite assumed protective effect hormonal profile. Which component of MS is likely to have the strongest influence, remains to be established.

\section{References}

1. Weiss R, Dziura J, Burgert TS et al. Obesity and the metabolic syndrome in children and adolescent. N Engl J Med 2004; 350 (23): 2362-2374.

2. Krahulec B. Metabolic syndrome and diabetes mellitus. Curr Clin Practice 2004; 3: 13-16.

3. Alberti KG, Eckel RH, Grundy SM et al. Harmonizing the metabolic syndrome. A Joint Interin Statement of the International Diabetes Federation task Force on Epidemiology and Prevention; World Heart Federation; International Atherosclerosis Society ; and International Association for the study of obesity. Circulation 2009; 120: 1640-1645.

4. Zeman D. Obezita a metabolický syndróm. Vnitř. Lék 2005; 51 (1): $72-75$.

5. Galajda P, Mokáň M, Prídavková D et al. Prevalencia diabetes melitus a metabolického syndrómu na Slovensku. Interná med. 2007; 7 (6): $325-331$.

6. Lietava J, Kosmálová V, Turek P. New metabolic syndrome in Slovakia. Nemesys. Bratislava; Fami, sro, 2011: 1-97.

7. Baráková A, Blažíček P, Námešná J. Prevalencia metabolického syndrómu a vybraných rizikových faktorov zdravia v populácií SR. Diabetes Obezita 2006; 6 (12): 18-28.

8. Linhart A. Aktuálni problémy v diagnostice preklinického orgánového postižení u arteriální hypertenze. Preventívni kardiologie. Mimoriadna príloha Postgrad Med 2006; 6: 26-30.

9. Souček M. Metabolický syndróm. Vnitř Lék 2009; 55 (7-8): 618-621.

10. Eguchi K, Schwartz JE, Roman MJ, Devereux RB, Gerin W, Pickering TG. Metabolic syndrome less strongly associated with target organ 
$279-282$

damage than syndrome components in a healthy, working population. J. Clin Hypertens 2007; 9 (5): 337-344.

11. Laurent S, Cockrocft J, Van Bortel L et al. Expert consensus document on arterial stiffnes: methodological issues and clinical applications. Eur Heart J 2006; 27 (21): 2588-2605.

12. Šimková A, Bulas J, Kozlíková K, Janiga I. Metabolický syndróm a tuhost' aorty. Vnitř Lék 2010; 56 (9): 1000-1004.

13. Leoncini G, Sacchi G, Ravera $M$ et al. Microalbuminuria is an integrated markar of subclinical organ damage in primary hypertension. J Hum Hypertens 2002; 16 (6): 399-404.

14. Pontremoli R, Leoncini G, Viazzi F et al. Evaluation of subclinical organ damage for risk assessment and treatment in the hypertensive patients: role of microalbuminuria. J Am Soc Nephrol 2006; 17 (4 Suppl 2): 112-114.

15. Cuspidi C, Zanchetti A. Evaluation of subclinical cardiac damage in arterial hypertension: from guidelines to clinical practice. Hipertens Riesgo Vasc 2010; 27 (1): 27-30.

16. Kawamoto R, Tomita H, Inoue A, Ohtsuka N, Kamitani A. Metabolic syndrome may be a risk factor for early carotid atherosclerosis in women but not in men. J Atheroscler Thromb 2007; 14 (1): 36-43.

17. Iglseder B, Cip P, Malaimare L., Ladumer G., Paulweber B. The metabolic syndrome is a stronger risk factor for early carotid atherosclerosis in women than in men. Stroke 2005; 36 (6): 1212-1217.
18. Lee HY, Oh BH. Aging and arterial stiffness. Circ J 2010; 74 (11): $2257-2262$.

19. Zatu MC, Van Rooven JM., Schulte AE. Smoking and vascular dysfunction in African and Caucasians from South Africa. Cardiovasc J Afr 2011; 22 (1): 18-24.

20. Kim YJ, KIM YJ., Cho BM, Lee S. Metabolic syndrome and arterial pulse wave velocity. Acta Cardiol 2010; 65 (3): 315-321.

21. Ferreira I., Boreham CA, Twisk JW, Gallagher AM, Young IS., Murray LJ, Stehouwer CD. Clustering of metabolic syndrome risk factors and arterial stiffness in young adults: the Northerm Ireland Young Hearts Project. J Hypertens 2007; 25 (5): 1009-1020.

22. Fábryová L. Vzt’ah viscerálnej obezity ku kardiometabolickým faktorom. Via pract 2008; 5 (3): 122-125.

23. Paes de Vasconcelos AV, Brauner de Moraes M, Solon NN, Filho AJI. Arterial hypertension in women. Prevalence and waist circumference in women. Int J Atheroscler 2008; 3 (3): 161-164.

24. Ford ES, Giles WH, Dietz WH. Prevalence of the metabolic syndrome among US adults: findings from the third National Health and Nutrition Examination Survey. JAMA 2002; 287: 356-359.

25. Mancia G, Parati G, Borghi C et al. Hypertension prevalence, awareness, control and association with metabolic abnormalities in the San Marino population: the SMOOTH study. J Hypertens 2006; 24 (5): 837-843. 